\title{
Maintaining the diversity of the professional healthcare workforce through higher education qualification routes
}

\author{
Thomas, Liz ${ }^{\text {a }}$, and Duckworth, Vicky \\ ${ }^{a}$ Faculty of Education, Edge Hill University, UK.
}

\begin{abstract}
In England many professional healthcare qualifications, including nursing, are only achievable through higher education, for which tuition fees are payable from this year (2017-18) onwards. This paper is concerned about maintaining both the number and diversity of healthcare professionals to meet the needs of a diverse and ageing population. It reviews student views and the available statistical evidence about the impact of the introduction of tuition fees on applicants, and literature and empirical evidence about what higher education institutions are doing to recruit and retain students from different backgrounds to meet the health needs of the population. It concludes that because professions such as nursing have traditionally recruited from a diverse population minimal knowledge or practical expertise has been developed to widen participation in healthcare education in general and nurse education in particular. Moving forward, the healthcare and higher education sectors will need to work in joined up ways to develop strategies to both attract and retain a wide range of diverse students to higher education professional healthcare qualification courses - and maintain the supply of qualified healthcare professionals.
\end{abstract}

Keywords: widening participation, diversity, healthcare, nurse education, tuition fees, institutional responses (maximum 6) 


\section{Introduction}

\subsection{Context}

Many healthcare professions in England face a double bind of both recruiting and retaining sufficient staff from diverse backgrounds to meet the health needs of the population. This challenge has become more complex with the introduction of tuition fees for healthcare higher education (HE) programmes and the UK's imminent departure from the European Union. This situation is especially acute in the field of nursing where there are 40,000 unfilled vacancies (Helm, 2017). Contributory factors include an ageing nursing workforce with a third planning to retire in the next ten years (IES, 2016), a reduction in the numbers of international qualified nurses applying to register in the UK due to the political unrest caused by Brexit (NMC, 2017) and thirdly, a drastic reduction in the numbers of students applying for nursing educational programmes in 2017 (see below).

Underpinning this paper are the assumptions that first, widening participation (WP) is necessary to recruit sufficient numbers of staff to meet demand from healthcare providers, and second that diversity of the healthcare workforce contributes to the quality of the care provided (Heaslip et al 2017). WP is understooad to mean expanding the diversity of students entering and succeeding in HE, with a particular focus on those from underrepresented and disadvantaged groups. Diversity includes a range of factors, including age, gender, ethnicity, class and educational background, sexuality and disablilty. In the context of healthcare in general, and nursing particular increasing diversity through WP includes recruiting more older students, more males, more Black and Minority Ethnic (BME) students, more students from low income and lower socio-economic groups, more students with non-traditional entry qualifications (i.e. not attained through the school system but gained subsequently through an alternative route), more students with disabilities and more students with caring responsibilities; no data is available on the sexuality of students.

\subsection{About the research}

This paper draws on two completed studies, and on-going research. The two completed studies were commissioned by Health Education England (HEE) to inform their work to widen participation in healthcare courses in HE that lead to professional registration. Initially we undertook a systematic literature review (Kaehne et al 2014) identifying interventions and approaches to facilitate WP in healthcare programmes. Subsequently, we undertook a mixed methods study exploring WP in healthcare programmes. Here we combined statistical analysis of data from the Higher Education Statistics Agency, with qualitative research with current students and recent graduates, and a review of institutional practices aimed at widening access and improving outcomes (student retention, attainment 
and progression into employment) amongst diverse students in healthcare programmes. Our on-going research is focusing more specifically on WP in nurse education. This has included an additional literature review (Heaslip et al, 2017), a survey of the nursing workforce, a review of applications data, and a stakeholder event to explore the views and experiences of practitioners in the health and HE sectors, and providing a rare opportunity for dialogue and learning between sectors. This paper draws from all of these sources to explore the actual and potential role of higher education institutions in widening participation in healthcare education, to both increase the number of healthcare professionals, and ensure the diversity is maintained to reflect the population that use health and social care services in England.

\section{Changes to the funding of healthcare education and the impact on the healthcare workforce}

\subsection{The funding changes}

In 2017 changes were implemented to the funding of healthcare education programmes in $\mathrm{HE}$ in England, shifting responsibility from the State to individual students and their families for both tuition fees and maintenance costs (DHSC, 2017). Healthcare students are no longer eligible to receive a bursary to contribute to their living costs, instead they are entitled to funding from the student loans system. In addition, healthcare students must now pay tuition fees similar to other under graduate students, currently up to $£ 9,250$ per year (https://www.gov.uk/student-finance/new-fulltime-students). Student loans cover both fees and living costs, and are repayable after graduation, once earnings exceed a minimum threshold. However, unlike other under-graduate courses, healthcare programmes such as nursing are genuinely full time over 45 weeks of the year; consisting of $50 \%$ theory and $50 \%$ practice. During the practice blocks student nurses work a 37.5-hour week, including night shifts, evenings and weekends, in a variety of healthcare settings and locations, so in effect the students are actually paying to deliver care round the clock. This also significantly reduces their capacity to undertake additional paid employment.

\subsection{Student views of the changes}

Before the implementation of these funding changes we interviewed 70 students and graduates from diversity backgrounds. In summary: $92 \%$ were over 21 of age on entry; $18 \%$ male; $24 \%$ BME; and $20 \%$ with a disability. $70 \%$ said that their annual family income was $£ 25,000$ or less, and a further $25 \%$ said it was between $£ 25,001-42,620 ; 46 \%$ said they were the first person in their family to enter HE; more than half lived with their partner 
and/or children, which was assumed to mean that they had a range of other responsibilities, and $25.7 \%$ said they had dependent children.

These students discussed the importance of financial issues in influencing their decisions to enter higher education, and continuing to shape their experiences once in HE. This was in contrast to previous research with low-income HE students in other disciplines in receipt of financial support (Bowes et al, 2016). For example, students explained how the availability of funding had enabled them to enter higher education:

I think finance is a big issue, which is why choosing an NHS sponsored course made such a big difference, because otherwise I wouldn't be able to do it. For me, finance was the only issue.

And how concern about funding had led them to postpone and plan for their studies.

I had to discuss with my husband quite a lot before we made that decision. This wasn't something that was just going to affect me.

It had also influenced decisions, such as to study at a local institution to keep maintenance costs low.

I think the fact that I could stay at home was a big issue, because that meant I could save quite a lot of money.

Once on course students again discussed many financial issues that impacted on their participation and experience. Some of the key issues are summarised by this student:

The main one for me was probably the financial side. I had a flat to run and a car and I had to travel. Sometimes I'd be travelling into uni for a one hour lecture. I had to work as well as studying to pay my rent and bills. I had two jobs. When you're on placement that is also a full-time job. Then you've got to do your coursework when on placement. Then you've got to do assessments as well sometimes which also overlap, then also working two jobs. So I was working seven days for a lot of weeks. That was stressful because you're tired and can't focus, but you need the money. So financially, I struggled. I got through it with support from my parents and working. I found it very difficult and if I'm honest, I wouldn't want anyone to do that because my grades did suffer through working. I had to retake one assessment because I just didn't have the time to complete it, but I needed to work to pay the bills. 


\subsection{A decline in applicants}

Given the importance attached to financial issues for students in our study, we were anticipating that the funding changes could make a significant impact on applications to healthcare programmes in general, and nursing courses in particular. Data from the Universities and Colleges Admissions Service (UCAS) showed that by the $15^{\text {th }}$ January deadline for the 2017 cycle there were 23\% fewer applicants to nursing from England, and $25 \%$ fewer applicants from the EU (excluding the UK) compared to the same time the previous year. Figures released by UCAS in August 2017 however found that there was a drop of about $8 \%$ in the number of students taking up nursing places. The data shows that there has been a decline in the number of mature applicants, and an increase in the number of young applicants. We propose to do further analysis to identify trends around who is and who is not participating in healthcare education, with a particular focus on nursing, compared to before the introduction of the changes to funding healthcare education programmes and the subsequent implementation of them.

\section{Higher education institutions' responses}

Given the changes in funding to healthcare education - and the pressing need for healthcare professionals, and universities own need for students in a marketized HE system - we anticipated that universities would be well-prepared to continue to attract a wide and diverse range of appliants that reflect the communities they serve - both as HE providers and in their role of supplying qualified healthcare professionals to the workforce. We looked at the literature to understand the knowledge-base about widening participation in these subjects (referenced above), and we explored interventions that universities has put in place through a sector-wide call for examples.

\subsection{Learning from the literature}

The first literature review by Kaehne et al (2014) identified only a limited number of studies (23) about WP in healthcare programmes, and these publications were mainly reporting on small-scale, isolated research projects. The examples identified and reviewed predominantly focused on raising awareness about healthcare programmes by providing further information, and overcoming academic barriers through changing admissions processes or providing alternative entry routes. The studies on retention and success clustered around the academic experience, particularly overcoming academic challenges, and the provision of additional student support. The more recent review of the literature about WP in nurse education (Heaslip et al, 2017) identified ten empirical studies, and similar themes emerged in relation to both access and success. The focus of much of the 
work is on academic barriers to participation and the construction of alternative entry pathways. Other studies focus on raising awareness of healthcare programmes and providing increased information about healthcare programmes. Similarly, once in HE, the published studies tend to focus on academic challenges and support. It can be concluded that the evidence base about how to expand the healthcare and nursing workforce through diversification is limited, informed by small-scale, and usually single institution studies. Furthermore, it is largely framed in negative terms directed towards what individual students lack, rather than looking at structural barriers and inequalities, that can be addressed by institutions and the healthcare sector - for example to capitalize on the experience and enthusiasm non-traditional students brought to the healthcare sector (Thomas et al, forthcoming).

\subsection{What higher education institutions are doing}

In light of the paucity of the literature, we invited HE providers in England to share with us about how they widen participation in healthcare programmes. The call was publicized through a number of on-line mailing lists and communities with a focus on WP and/or healthcare education, and respondents were asked to complete a template to provide information in response to specific questions. Unlike other similar calls undertaken by the authors we received a small response of 18 examples of activities from 14 institutions. Most of the examples provided focused on widening access (11 out of 18 examples). Fewer examples focused on continuation and completion, improving attainment, and progression to PG study or health-related employment. Some of the examples spanned several stages in the student journey.

The widening access examples provided cover a range of activities including open days, taster sessions, summer schools, mentoring, access courses and contextualised application processes. This is broadly in line with what we know are the most common approaches to widening access adopted by higher education institutions more generally (Bowes et al 2013); there does not appear to be any additional focus on financial issues, which is surprising.

Activity to support continuation, completion and attainment tends to be less targeted than access activity, with many institutions choosing to mainstream provision such as pastoral care and support with academic development. This, perhaps, may explain why we received fewer specific examples of activities under this heading. Furthermore, the examples submitted contained very little activity specifically promoting progression to health-related employment or postgraduate study. Five HEIs submitted examples of activities that contribute to promoting progression, however, nearly all of these are outreach activities targeted at school pupils, sixth-form students or other groups outside higher education. 
None are examples of work with current undergraduates or recent graduates. While healthcare students may benefit from more generic activities to support progression provided by HEIs, it is surprising how little tailored support is offered to launch graduate careers in their chosen healthcare professions - especially given the different demands of their courses, which combine both academic study and extensive working in practice.

\subsection{Evaluating effectiveness and impact}

It is also worth noting that the literature identifies a lack of evidence about the impact of the interventions, and this is reflected in the practice examples. Many of the examples submitted include feedback from participants in activities on their perceptions of the helpfulness and self-reported impact. Very few include follow-up information, for example, changes in achievement or the proportions of participants in activities who go on to submit applications to healthcare courses. Even with this information, without any comparator group it is not possible to determine to what extent it is the intervention in question that has delivered the impact, or something else, or whether students would have progressed anyway. HE institutions need to be encouraged and supported to carry out more robust and longer-term evaluations of the impacts and effectiveness of their WP activities in the field of health and social care.

\section{Conclusions, implications and recommendations}

Healthcare professionals, especially nurses, have traditionally been recruited from a more diverse population than the wider student population (Woodfield, 2014). The literature and empirical research presented here suggests that there is a lack of knowledge and expertise amongst healthcare and nursing education professionals about effective strategies to maintain and increase recruitment and successful completion of students from diverse groups, which is now becoming problematic.

A WP strategy needs to be developed and implemented at national and local levels. This should be based on a partnership approach bringing together the health, social care and HE sectors to foster dialogue and change. This could build on existing WP partnerships in England, but attention needs to be paid to the unique context of healthcare professionals who have a very full timetable, and who contribute directly to patient care, and the associated importance of funding issues and financial support to many of these students. The approach should thus be informed by an expanded evidence base about the issues and effective practices for diversity in healthcare education in general and nursing in particular. Our research suggests that a strategic, inclusive approach is required, which identifies and addresses the barriers, but which also illuminates the key enabling factors that attract and retain a wide range of students that reflect the communities they serve to higher education 
professional healthcare qualification courses. For example, we found that people's commitment and passion for working in these fields is vital, and should be tapped into to support recruitment and success in HE and beyond (Thomas et al 2017), and not be exploited.

\section{References}

Bowes, L. Jones, S. Thomas, L. Moreton, R. Birkin, G. Nathwani, T. (2013) The Uses and Impact of HEFCE Funding for Widening Participation. Bristol: HEFCE

Bowes, L., Moreton, R., Thomas, L., Sheen, J., Birkin, G. and Richards, S. (2016) Evaluation of the National Scholarship Programme. Bristol: HEFCE

Department of Health and Social Care (DHSC) (2017) NHS Bursary reform. London: DHSC https://www.gov.uk/government/publications/nhs-bursary-reform/nhs-bursaryreform accesses 9/2/18

Helm, T. (2017) Recruitment crisis hits NHS with one in nine posts currently vacant. The Observer, $9^{\text {th }}$ May 2017 https://www.theguardian.com/society/2017/may/13/royalcollege-nursing-nhs-recruitment-crisis

https://www.theguardian.com/society/2017/may/13/royal-college-nursing-nhsrecruitment-crisis, accessed 9/2/18

Heaslip, V., Board, M., Duckworth, V. and Thomas, L. (2017) Widening Particiption in Nurse Education; An Integrative Literature Review. Nurse Education Today. ISSN 0260-6917 DOI https://doi.org/10.1016/j.nedt.2017.08.016.

Institute for Employment Studies (IES) (2016) One in three nurses to reach retirement age within ten years. Brighton: IES http://www.employment-studies.co.uk/news/one-threenurses-reach-retirement-age-within-ten-years, accessed 9/2/18

Kaehne, A., Maden, M., Thomas, L., Brown, J., Roe, B., (2014) Literature Review on approaches and impact of interventions to facilitate Widening participation in Healthcare Programmes. Ormskirk: Edge Hill University.

Nursing and Midwifery Council (NMC) (2017) Report on European Nurses and Midwives. https://www.nmc.org.uk/globalassets/sitedocuments/special-reports/nmc-eu-report-june2017.pdf

Thomas, L. et al (2017) Working paper 1: Persistent passion: Implications for policy and practice in widening access and success in healthcare education, http://www.lizthomasassociates.co.uk/wp-nursing.html, 9/2/18

Woodfield, R. (2014) Undergraduate retention and attainment across the disciplines. York: Higher Education Academy 